\title{
COMPLEX SYSTEMS IN HUMAN DEVELOPMENT: SEXUAL DIMORPHISM IN TEETH AND FINGERPRINTS OF AUSTRALIAN TWINS
}

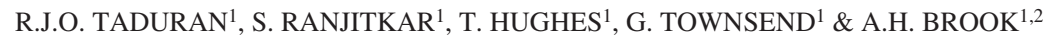 \\ ${ }^{1}$ Craniofacial Biology Research Group, School of Dentistry, University of Adelaide, Australia. \\ ${ }^{2}$ School of Dentistry, Queen Mary University of London, UK.
}

\begin{abstract}
Human teeth and fingerprints have similar embryological origin from epithelial-mesenchymal interactions. This study aims to determine the nature and extent of sexual dimorphism in fingerprints and teeth of twins; investigate the influences of genetic, epigenetic and environmental factors on observed variation; identify possible developmental associations between the phenotypes; and explore whether both systems display the features of complex adaptive systems. Mesiodistal (MD) measurements from both primary and permanent teeth and ridge density $(\mathrm{RD})$ from three different finger areas, namely ulnar $(\mathrm{U})$, radial $(\mathrm{R})$, and proximal $(\mathrm{P})$, from fingerprints of the same set of monozygotic and dizygotic Australian twins (28 males and 31 females aged 8 to 10 years, and aged 13 to 16 years, respectively) were collected and analysed. Sexual dimorphism was observed in both the primary and permanent dentitions, with the latter showing greater magnitude of differences than the former. There was no observed sexual dimorphism in the fingerprints of the 8 to 10 year cohort, but a few finger areas (left index U, right index R, left little R, and left little P) of the 13- to 16-year cohort exhibited significant differences, showing that friction ridges expand over time. It was concluded that both dentition and dermatoglyphics display characteristics of complex adaptive systems.

Keywords: complex adaptive system, dentition, tooth size, dermatoglyphics, fingerprints, human development, mesiodistal, ridge density, sexual dimorphism.
\end{abstract}

\section{INTRODUCTION}

Sexual dimorphism is defined as the phenotypic or observable difference between males and females of the same biological species. A number of studies have been conducted on sexual dimorphism in the human dentition. In general, males have larger crown diameters than females [1,2], and sexual dimorphism is greater in permanent than in primary dentition [2,3]. Meanwhile, studies on sexual dimorphism in adult human dermatoglyphs reveal that males have fewer ridges than females $[4,5]$.

The development of the human dentition and of dermatoglyphs has similar embryological origin from epithelial-mesenchymal interactions [6]. During embryonic growth, patterning, or the establishment of groups of cells in the proper relationship to each other and to surrounding tissues, occurs. Patterning is a longitudinal event that eventually leads to differentiation of cells to assume specialised functions and shapes. Primary teeth start to develop around 4 to 6 weeks in utero [6], while ridged skin begins to form around 10 to 16 weeks in utero [7].

Human development in general is a complex adaptive process that is influenced by genetic, epigenetic and environmental factors [8]. The genetic factors interact with epigenetic and environmental elements at the molecular level and form complex networks within the cells, and from these dynamics arise the higher level tissues. Sexual dimorphism has been suggested by some researchers to be 
governed by sex chromosomes $[9,10]$ but there have been others who have suggested that hormones are also important $[11,12]$. Dental and dermatoglyphic patterns develop in utero, and once stabilised, their unique and persistent morphology makes them valuable models in studying sexual dimorphism. This study aimed to determine the nature and extent of sexual dimorphism in mesiodistal crown measurements of teeth and ridge density counts of fingerprints of twins; to investigate the influences of genetic, epigenetic and environmental factors; and to identify possible developmental associations and covariance of the studied phenotypes.

\section{MATERIALS AND METHODS}

Twin samples were obtained from the ongoing longitudinal studies of the Craniofacial Biology Research Group in the School of Dentistry at the University of Adelaide [13], which is one of the four most extensive investigation of its type in the world [14]. Serial dental casts of primary and permanent dentitions, and rolled ink prints of fingers of individuals aged 8 to 10 years and 13 to 16 years of the same cohort of monozygotic and dizygotic Australian twins (28 males and 31 females) were collected and analysed. Dental casts showing wear, caries, or restorations and ten-prints with smudge ink and scarred patterns in any of the fingerprints were excluded.

Mesiodistal crown diameter (MD) was measured as the distance between the mesial and distal contact points of the tooth crown $[1,15]$ by using a $2 \mathrm{D}$ imaging system. Dental casts were oriented using an adjustable stage to obtain the correct plane or angle before taking images and a calibrated Image J [16] software was used to digitise landmarks (Fig. 1). Measurements were obtained for central incisors (I1), lateral incisors (I2), canines (C), first molars (M1) and second molars (M2) of primary and permanent teeth.

Ridge density (RD) was measured by counting friction ridges diagonally on a square measuring $5 \mathrm{~mm} \times 5 \mathrm{~mm}$ to isolate ridges within a well-defined area [4,17]. Measurements were obtained in three different finger ridge locations, namely, distal ulnar (U), distal radial (R), and proximal (P), of each of the ten fingerprints in both cohorts. The three areas were located by dividing the rolled prints into four sectors, with two perpendicular axes that cross two ridges above the centre [17]. Fingers

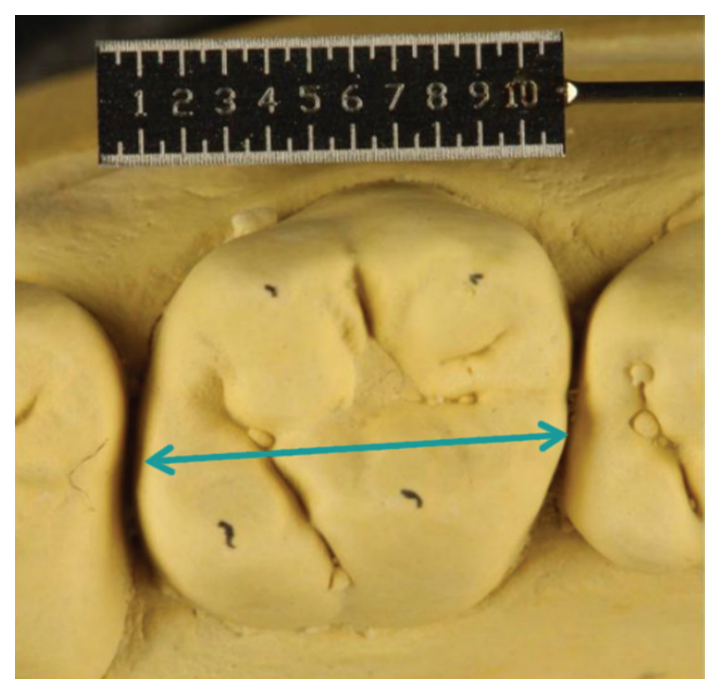

Figure 1: Mesiodistal (MD) measurement on a permanent upper first molar from the occlusal view. 


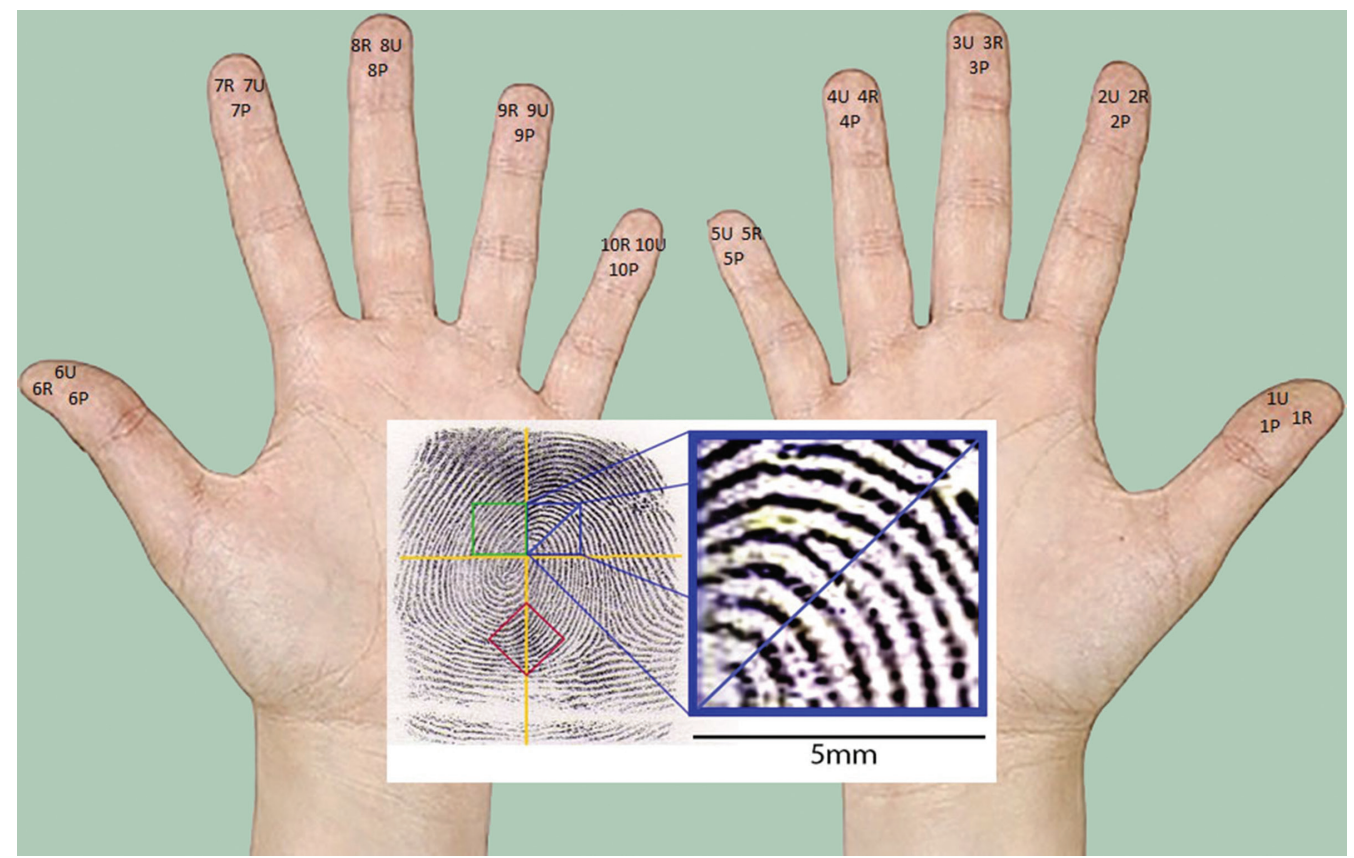

Figure 2: Locations of fingerprint areas - distal ulnar $(\mathrm{U})$, distal radial $(\mathrm{R})$ and proximal $(\mathrm{P})$ - on each finger, and an enlarged $5 \mathrm{~mm} \times 5 \mathrm{~mm}$ area to facilitate ridge density $(\mathrm{RD})$ count.

were assigned with a numerical order 1-10, with finger 1 being the right thumb and finger 10 being the left little finger (Fig. 2).

Data were statistically analysed using XLSTAT statistical software. Descriptive statistics including means, standard deviations (SD) and coefficients of variation (CV) were computed for MD and RD. Differences between sexes and sides were calculated using student's unpaired t-test. Differences among fingers and finger areas were examined with analysis of variance (ANOVA). Finger ridge differences between age groups were compared with paired t-test. Pearson's coefficient was calculated to examine correlations between the variables.

\section{RESULTS}

MD measurements and RD counts were normally distributed, and results of intra and inter-operator repeatability tests showed that errors in methodological measurements were negligible and not likely to bias data. Shown in Table 1 are the mean values, SD and CV of mesiodistal (MD) measurements of primary and permanent teeth.

Highlighted in yellow background and bold text are the sexually dimorphic dental measurements, where mean values are different between sexes at $\mathrm{p}<0.05$. Mean values of MD crown dimensions of males were consistently greater compared to females in all teeth. Permanent dentitions displayed greater sexual dimorphism compared to primary dentitions. There were no left-right differences observed in MD measurements of all primary and permanent dentitions.

Shown in Table 2 are the mean values, SD and CV of ridge density (RD) counts of fingerprints of 8 to 10 years old cohort and 13 to 16 years old cohort.

All mean values of RD based on finger type and finger area were statistically different to each other at $\mathrm{p}<0.05$. Highlighted in blue background and italics are the RD counts that were found to 


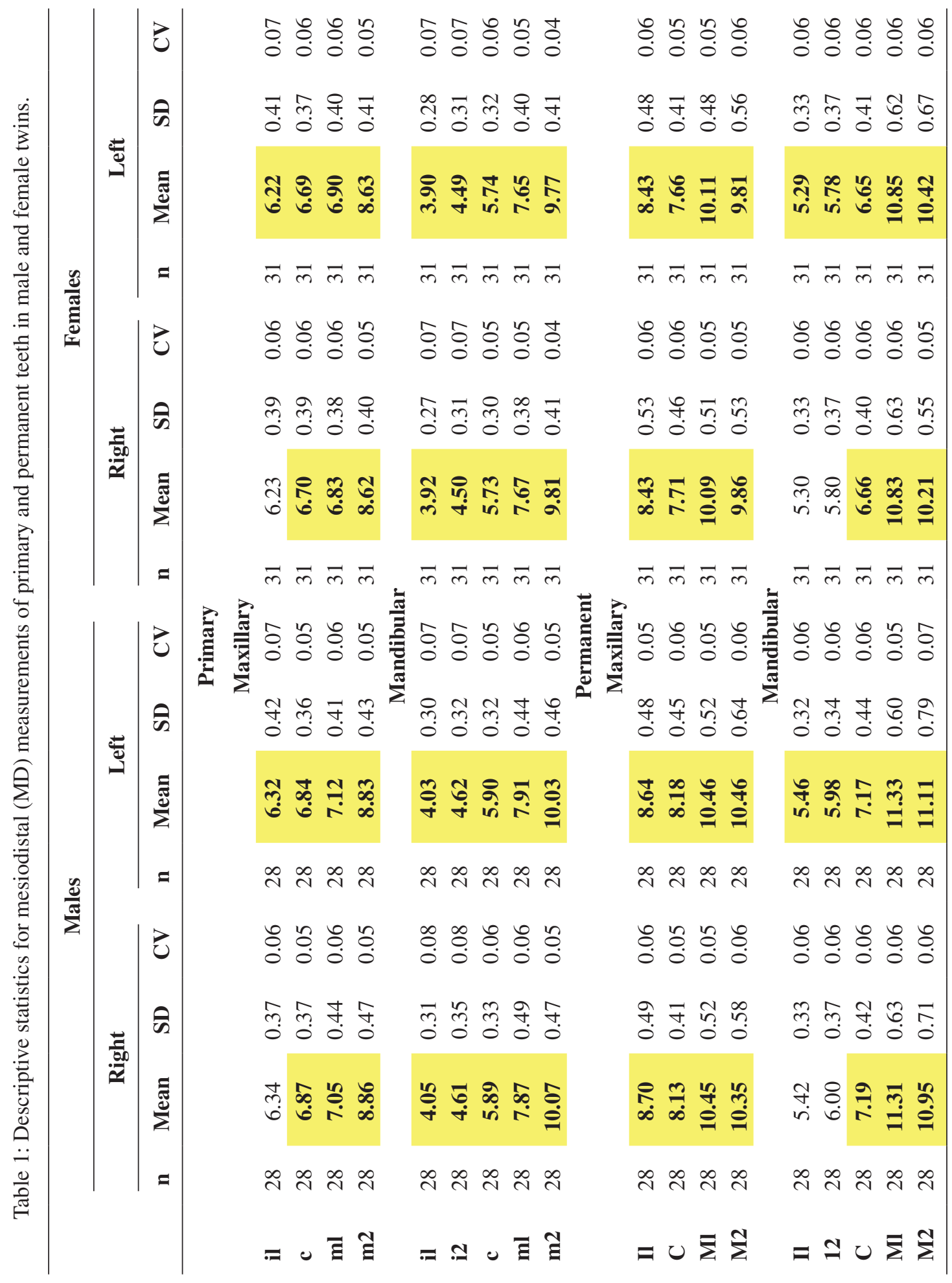




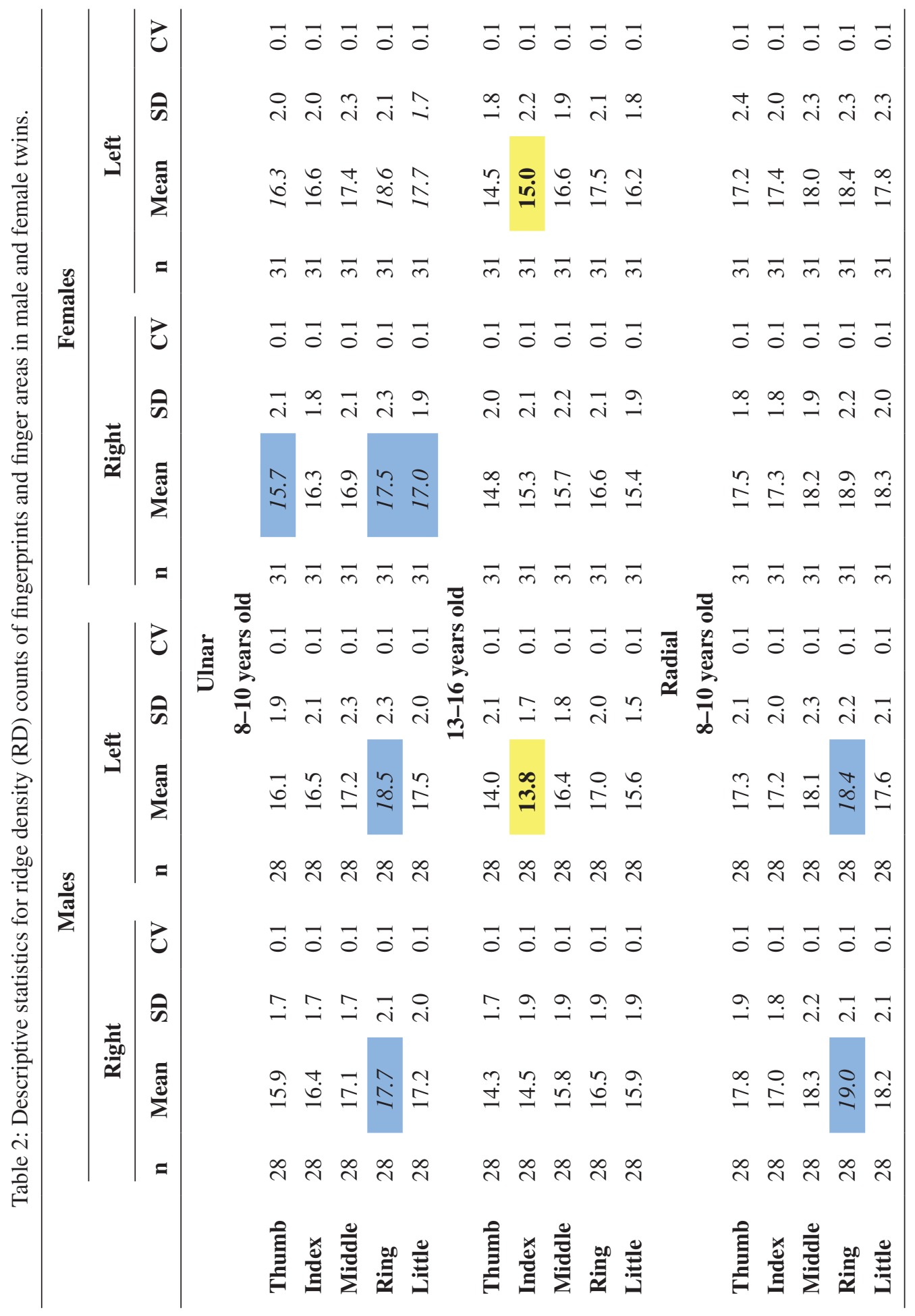




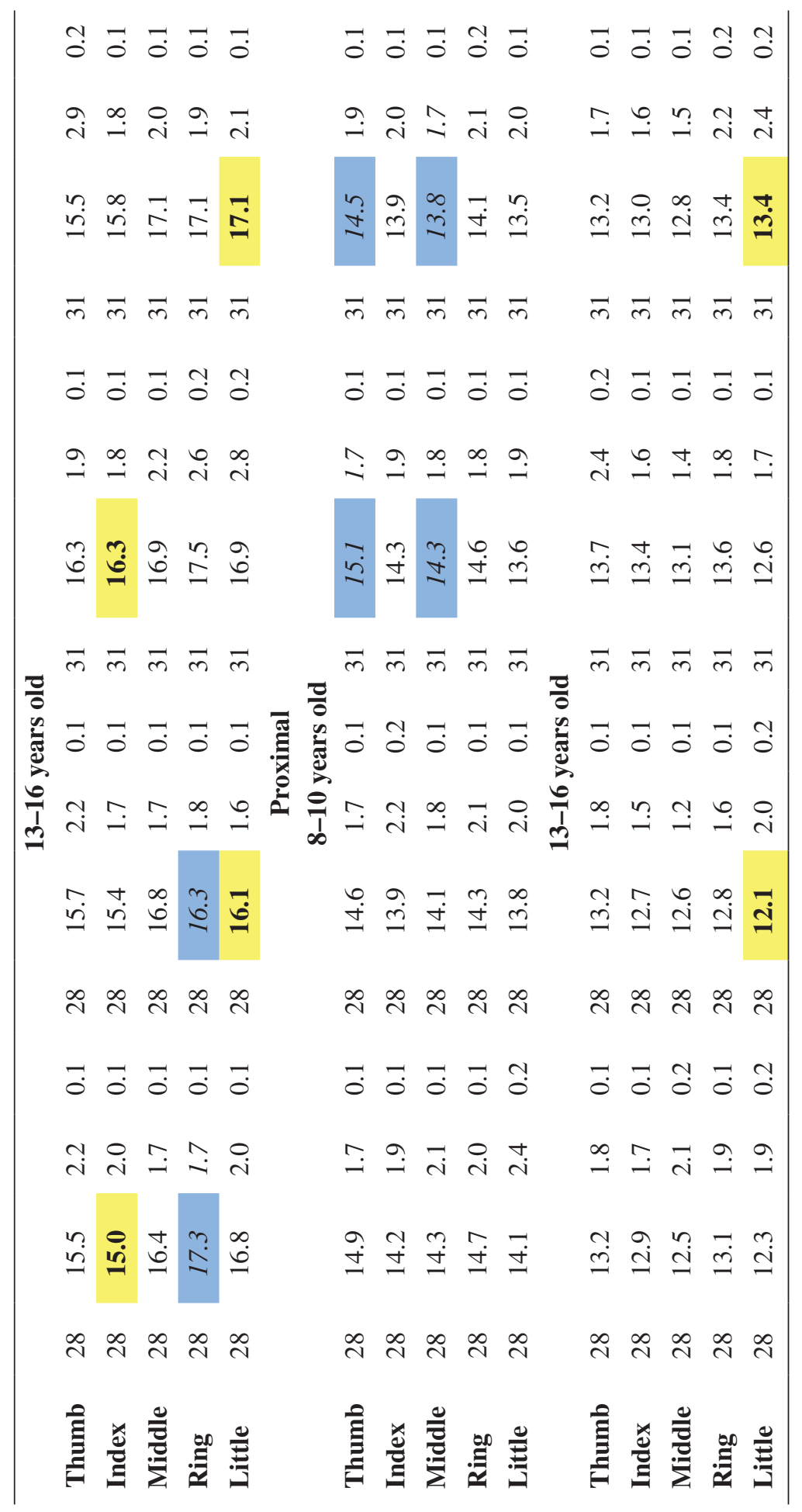


Table 3: Pearson correlation coefficients of the dental (mesiodistal width) and dermatoglyphic (ridge density) traits.

\begin{tabular}{lcccc}
\hline \multirow{2}{*}{ Finger Area } & Males & Females & Males & Females \\
\cline { 2 - 5 } & \multicolumn{4}{c}{ Primary } \\
Maxillary & MD \\
Ulnar & $\mathbf{0 . 2 0}$ & $\mathbf{0 . 1 6}$ & $\mathbf{0 . 1 6}$ & $\mathbf{0 . 1 3}$ \\
Radial & $\mathbf{0 . 1 2}$ & $\mathbf{0 . 1 1}$ & 0.11 & 0.08 \\
Proximal & -0.03 & $\mathbf{- 0 . 1 2}$ & -0.04 & 0.00 \\
& & Mandibular & MD & \\
Ulnar & $\mathbf{0 . 2 7}$ & $\mathbf{0 . 2 5}$ & $\mathbf{0 . 3 8}$ & $\mathbf{0 . 3 0}$ \\
Radial & $\mathbf{0 . 1 3}$ & $\mathbf{0 . 1 6}$ & $\mathbf{0 . 2 4}$ & $\mathbf{0 . 2 3}$ \\
Proximal & $\mathbf{- 0 . 0 7}$ & $\mathbf{- 0 . 1 6}$ & -0.11 & -0.01 \\
\hline
\end{tabular}

be statistically different on both sides. More differences were observed in the younger (8-10 years old) cohort. The ulnar area (U) was the most irregular of all finger ridge areas in terms of left-right discrepancies, yet it was observed to have smaller RD in the right side, which indicates thicker finger ridges. Most of the thicker ridges in the radial $(\mathrm{R})$ and proximal $(\mathrm{P})$ areas were observed in the left fingers.

Highlighted in yellow background and bold text are the sexually dimorphic dermatoglyphic measurements, where mean values are different between sexes at $\mathrm{p}<0.05$. Only a few sexually dimorphic finger ridge areas were observed to be greater from the older cohort (13-16 years old), with smaller mean values for $\mathrm{RD}$ in males, which indicates thicker and fewer friction ridges within the $5 \mathrm{~mm}^{2}$ square. Based on paired t-test, all mean values of RD are different between age groups at $\mathrm{p}<0.05$, with the older cohort showing smaller RD values compared to the younger group.

Pearson's coefficients (r) between teeth and fingerprints are presented in Table 3. Highlighted in yellow background and bold text are the significant correlations between dental trait MD and dermatoglyphic characteristic RD (ulnar, radial and proximal) at $\mathrm{p}<0.05$. Overall, the correlations between teeth and fingerprints are low, but the RD in the ulnar area emerged with the highest coefficients with MD diameter of the maxillary and mandibular dentition in both sexes.

Correlation coefficients were calculated within groups of dental and dermatoglyphic variables at $\mathrm{p}<0.05$. All MD diameters taken from different tooth types were positively correlated to each other in the primary teeth (0.31-0.95). Only some MD measurements (71 of 231 in males, 119 of 231 in females) were positively correlated with each other in the permanent teeth (0.40-0.84), and more significant values were observed in females than males. Meanwhile, only some RD counts from different fingers and areas were positively correlated to each other (312 of 435 in young males and 252 of 435 in young females, 147 of 435 in old males and 112 of 435 in old females), with more significant values in males and the young cohort. Greater $r$ values were observed in the old cohort ( 0.35 to $0.75)$ compared to the young cohort (0.19 to 0.59$)$.

\section{DISCUSSION}

The degree and patterning of sexual dimorphism in the dentition varies according to tooth type. Our observation of the permanent dentition showing more pronounced sexual dimorphism than primary 
dentition agrees with previous findings $[1,2]$. The permanent lower canines displayed the largest sexual dimorphism in MD measurements, similar to the results of Garn et al. [3] and Ribeiro et al. [12] who pointed out that dental development might occur under fairly high levels of testosterone influence, and this could explain the differences in sexual dimorphism between primary and permanent teeth of same individuals.

The degree and patterning of sexual dimorphism in the dermatoglyph varies according to the finger area and finger type. In this study, there was no observed sexual dimorphism in the 8 to 10 year old group, while fingerprints of the 13 to 16 year old group displayed sexual dimorphism in the ulnar and radial areas of the index finger, and radial and proximal areas of the little finger. Few studies have investigated subadult fingerprints, and our results could be preliminary empirical evidence that friction ridges expand as individuals grow and develop, and possibly more so in males than females. It seems that sexual dimorphism in dermatoglyphic development commences during puberty, when a testosterone surge occurs in males [18].

There are three surges of testosterone that occur in normal male development. The first surge begins at around the 7th to 9th week of pregnancy, following testicular differentiation, and the testosterone level is at its highest around the 14th week [19,20]. The second surge occurs after birth due to the reduction of oestrogen produced by the placenta [18]. The third surge, as previously mentioned, occurs during puberty.

Primary dentition starts to develop at around 4 to 6 weeks in utero [6] and continues until around one year after birth. Permanent dentition begins to form 14 weeks in utero and continues to develop until at around 14 years of age [21]. Meanwhile, primary ridge formation begins at around 10 to 16 weeks and ends on the 17th week, then secondary ridges form until the 24th week in utero [7]. Our results suggest that the first two testosterone surges have a critical role in the sexual dimorphism of both the primary and permanent dentitions, while the third testosterone surge influences the sexual dimorphism of the fingerprints.

Human development is a complex adaptive process [8] and the human body is a complex adaptive system. This study has shown that both teeth and fingerprints are interconnected, yet they still have a degree of autonomy. They share a similar embryological origin and epithelial-mesenchymal interactions [6], yet they develop and interact with epigenetic and environmental factors differently. The interactions may be unpredictable, with no central control, but they are not random, as regularities and patterns emerge to find the best fit with the environment.

This research is the first to study both human dental and dermatoglyphic traits. Although a number of studies have been conducted on human dentition and dermatoglyphs separately, no attempt has been made previously to explore possible correlations between the two. This research furthers the investigation on the complex mechanisms and interactions occurring during dental, dermatoglyphic and general development with mesiodistal (MD) diameters of the teeth and ridge density (RD) counts of the fingerprints. In the future, more dental and dermatoglyphic traits could be studied together.

\section{ACKNOWLEDGEMENTS}

The authors wish to thank The Australian Dental Research Foundation (ADRF), the NHMRC of Australia, Australian Twin Registry and Australian Multiple Birth Association.

\section{REFERENCES}

[1] Moorrees, C.F.A., Thomsen, S.O., Jensen, E. \& Yen, P.K., Mesiodistal crown diameters of the deciduous and permanent teeth in individuals. Journal of Dental Research, 36, pp. 39-47, 1957. http://dx.doi.org/10.1177/00220345570360011501 
[2] Ribeiro, D., Sampson, W., Hughes, T., Brook, A. \& Townsend, G., Sexual dimorphism in the primary and permanent dentitions of twins: an approach to clarifying the role of hormonal factors (Chapter 5). New Directions in Dental Anthropology: Paradigms, Methodologies and Outcomes, eds. G. Townsend, E. Kanazawa \& H. Takayama, University of Adelaide Press: South Australia, pp. 46-64, 2012.

[3] Garn, S.M., Lewis, A.B., Swindler, D.R. \& Kerewsky, R.S., Genetic control of sexual dimorphism in tooth size. Journal of Dental Research, 46, pp. 963-972, 1967. http://dx.doi.org/10.1177/00220345670460055801

[4] Acree, M.A., Is there a gender difference in fingerprint ridge density? Forensic Science International, 102, pp. 35-44, 1999. http://dx.doi.org/10.1016/S0379-0738(99)00037-7

[5] Taduran, R.J.O., Tadeo, A.K.V., Escalona, N.A.C. \& Townsend, G.C., Sex determination from fingerprint ridge density and white line counts in Filipinos. HOMO - Journal of Comparative Human Biology, 2015.

http://dx.doi.org/10.1016/j.jchb.2015.11.001

[6] Nanci, A., Ten Cate's Oral Histology: Development, Structure, and Function, 7th edn., Elsevier Health Sciences: Missouri, pp. 16-107, 2008.

[7] Kücken, M. \& Newell, A.C., Fingerprint formation. Journal of Theoretical Biology, 235, pp. 71-83, 2005. http://dx.doi.org/10.1016/j.jtbi.2004.12.020

[8] Brook, A.H., Brook O’Donnell, M., Hone, A., Hart, E., Hughes, T.E., Smith, R.N. \& Townsend, G.C., General and craniofacial development are complex adaptive processes influenced by diversity. Australian Dental Journal, 59S, pp. 13-22, 2014. http://dx.doi.org/10.1111/adj.12158

[9] Guatelli-Steinberg, D., Sciulli, P.W. \& Betsinger, T.K., Dental crown size and sex hormone concentrations: another look at the development of sexual dimorphism. American Journal of Physical Anthropology, 137, pp. 324-333, 2008. http://dx.doi.org/10.1002/ajpa.20878

[10] Alvesalo, L., Human sex chromosomes in oral and craniofacial growth. Archives of Oral Biology, 54S, pp. 18-24, 2009.

http://dx.doi.org/10.1016/j.archoralbio.2008.06.004

[11] Dempsey, P.J., Townsend, G.C. \& Richards, L.C., Increased tooth crown size in females with twin brothers: evidence for hormonal diffusion between human twins in utero. American Journal of Human Genetics, 11, pp. 577-586, 1999.

[12] Ribeiro, D.C., Brook, A.H., Hughes, T.E., Sampson, W.J. \& Townsend, G.C., Intrauterine hormone effects on tooth dimensions. Journal of Dental Research, 92, pp. 425-431, 2013. http://dx.doi.org/10.1177/0022034513484934

[13] Townsend, G., Bockmann, M., Hughes, T., Mihailidis, S., Seow, K.W. \& Brook, A., New approaches to dental anthropology based on the study of twins (Chapter 2). New Directions in Dental Anthropology: Paradigms, Methodologies and Outcomes, eds. G. Townsend, E. Kanazawa \& H. Takayama, University of Adelaide Press: South Australia, pp. 10-21, 2012.

[14] Hughes, T.E., Townsend, G.C., Pinkerton, S.K., Bockmann, M.R., Seow, W.K., Brook, A.H., Richards, L.C., Mihailidis, S., Ranjitkar, S. \& Lekkas, D., The teeth and faces of twins: providing insights into dentofacial development and oral health for practicing oral health professionals. Australian Dental Journal, 59S, pp. 101-116, 2014.

http://dx.doi.org/10.1111/adj.12101 
[15] Brook, A.H., Smith, R.N., Elcock, C., al-Sharood, M.H., Shah, A.A., Khalaf, F., Robinson, D.L., Lath, D.L. \& Karmo, M., The measurement of tooth morphology: validation of an image analysis system. 13th International Symposium of Dental Morphology. ed. E. Zadzinska, University of Lodz Press: Lodz, pp. 475-482, 2005.

[16] Schneider, C.A., Rasband, W.S. \& Eliceiri, K.W., NIH Image to ImageJ: 25 years of image analysis. Nature Methods, 9, pp. 671-675, 2012.

http://dx.doi.org/10.1038/nmeth.2089

[17] Gutiérrez-Redomero, E., Alonso, C., Romero, E. \& Galera, V., Variability of fingerprint ridge density in a sample of Spanish Caucasians and its application to sex determination. Forensic Science International, 180, pp. 17-22, 2008. http://dx.doi.org/10.1016/j.forsciint.2008.06.014

[18] Griffin, J.E. \& Wilson, J.D., Disorders of the testes and the male reproductive tract (Chapter 18). Williams Textbook of Endocrinology, 10th edn., eds. P.R. Larsen, H.M. Kronemberg, S. Melmed \& K.S. Polonsky, W.B. Saunders Company: Philadelphia, pp. 709-770, 2003.

[19] Reyes, F.I., Boroditsky, R.S., Winter, J.S.D. \& Fairman, C., Studies on human sexual development. II. Fetal and maternal serum gonadotropin and sex steroid concentrations. Journal of Clinical Endocrinology and Metabolism, 38, pp. 612-617, 1974. http://dx.doi.org/10.1210/jcem-38-4-612

[20] Knickmeyer, R.C. \& Baron-Cohen, S., Fetal testosterone and sex differences. Early Human Development, 82, pp. 755-760, 2006.

http://dx.doi.org/10.1016/j.earlhumdev.2006.09.014

[21] AlQahtani, S.J., Hector, M.P. \& Liversidge, H.M., Brief communication: the London atlas of human tooth development and eruption. American Journal of Physical Anthropology, 142, pp. 481-490, 2010.

http://dx.doi.org/10.1002/ajpa.21258 